\title{
METABOLIC EFFECTS OF SULFONYLUREAS IN NORMAL MEN AND IN VARIOUS TYPES OF DIABETIC PATIENTS*
}

\section{By Stefan S. Fajans, Lawrence H. Louis, Allen R. Hennes $\dagger$,}

Bernardo L. Wajchenberg $\ddagger$, Robert D. Johnson, Robert D.

Gittler, Irving P. Ackerman, and Jerome W. Conn

Metabolism Research Unit of the Division of Endocrinology and Metabolism, Department of Internal Medicine, University of Michigan Medical School, Ann Arbor, Mich.

The studies described in this report were initiated in an effort to elucidate the mechanism of action of the sulfonylurea compounds. It seemed to us that a broad clinical investigative approach, involving the study of a large number of conditions in which the metabolism of carbohydrate is disturbed, was most likely to eliminate quickly a number of possible modeş of action and to define more sharply the areas upon which further effort should be concentrated. Thus, extensive metabolic-balance studies and numerous individual testing procedures have been performed before, during, and following the administration of carbutamide (BZ-55) and/or tolbutamide (Orinase $\$$ ) in the following subjects: (1) healthy young men; (2) three middle-aged, obese, stable diabetics; (3) an unstable diabetic of normal weight; (4) a patient with lipo-a trophic diabetes; (5) a totally depancreatized woman; (6) patients with coexisting diabetes mellitus and Addison's disease, familial diabetes and Cushing's syndrome, and diabetes and panhypopituitarism; and (7) an acromegalic with mild diabetes.

Although the data reported below do not define a specific mode of action of the sulfonylurea compounds, they eliminate from consideration a number of important possibilities.

\section{Results}

Administration of the sulfonylurea compounds to normal men produces definite hypoglycemia. A single dose of either 3 or $6 \mathrm{gm}$. of tolbutamide given to 2 normal subjects in the fasting state produced decreases in blood sugar of 35 to 60 per cent.

In normal subject D. M., administration of $6 \mathrm{gm}$. of carbutamide as a single dose on 2 consecutive days, followed by a dose of $31 / 2$ and $4 \mathrm{gm}$. daily in divided doses for the next 2 days, produced a fall in the level of fasting blood sugar from 78 to $24 \mathrm{mg}$. per cent (FIGURE 1). Subsequent administration of $3 \mathrm{gm}$. daily in divided doses kept levels of fasting blood sugars fairly constant at about $60 \mathrm{mg}$. per cent.

In the same normal subjects, when the compounds were administered at

* The work reported in this paper was supported by grants from The Upjohn Company, Kalamazoo, Mich.; Eli Lilly and Company, Indianapolis, Ind.; and Research Grant No. A-888 from the United States Public Health Service.

$\dagger$ Post-doctorate Research Fellow, United States Public Health Service. Present address: Medical Department, Brookhaven National Laboratory, Upton, N. Y.

$\ddagger$ Latin-American Fellow (São Paulo, Brazil) of the American College of Physicians.

$\S$ The Upjohn Company, Kalamazoo, Mich. 


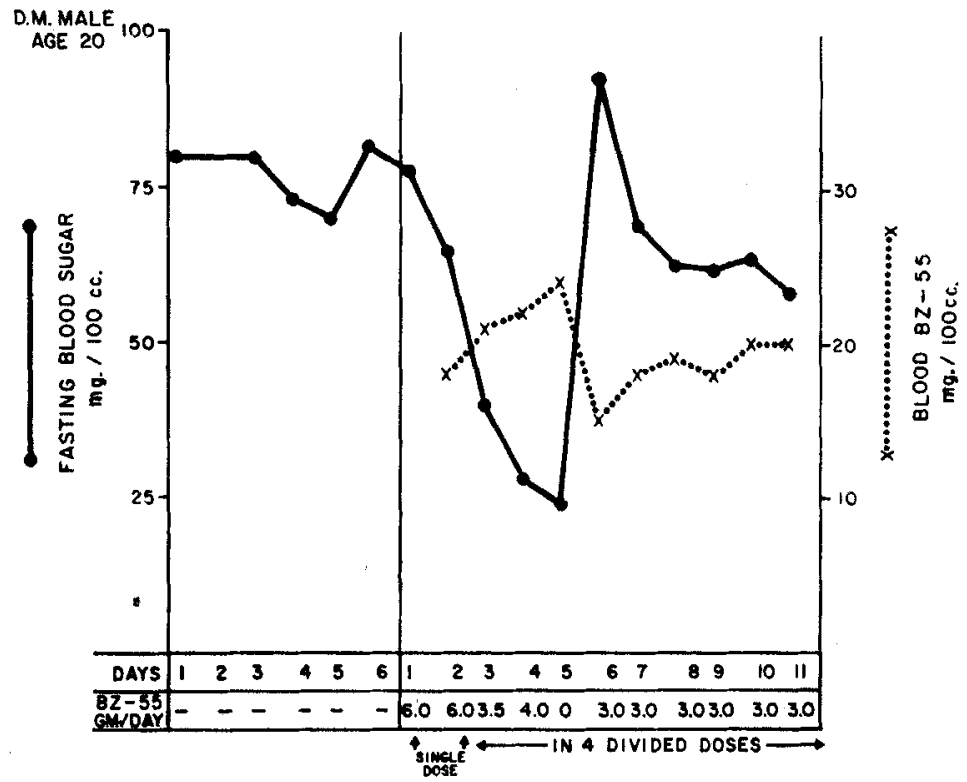

FIGURF 1. Effect of the administration of carbutamide (BZ-55) on fasting blood sugar in a normal subject.

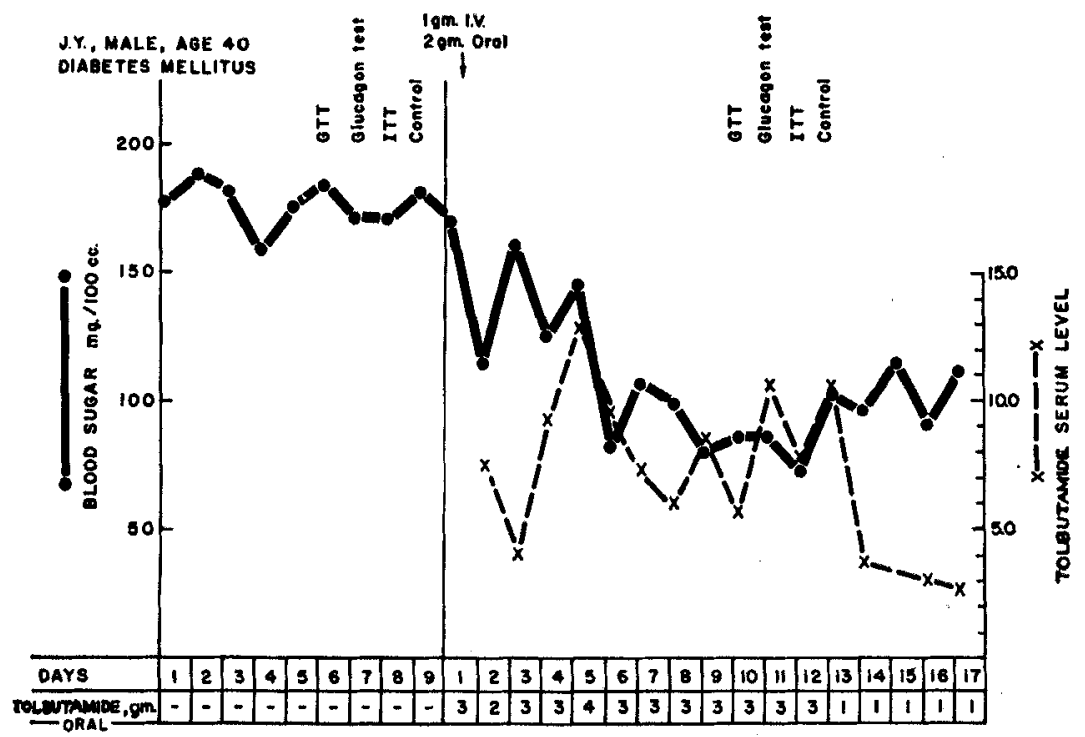

FIGURE 2. Effect of the administration of tolbutamide on fasting blood sugar in a patient with diabetes mellitus. 

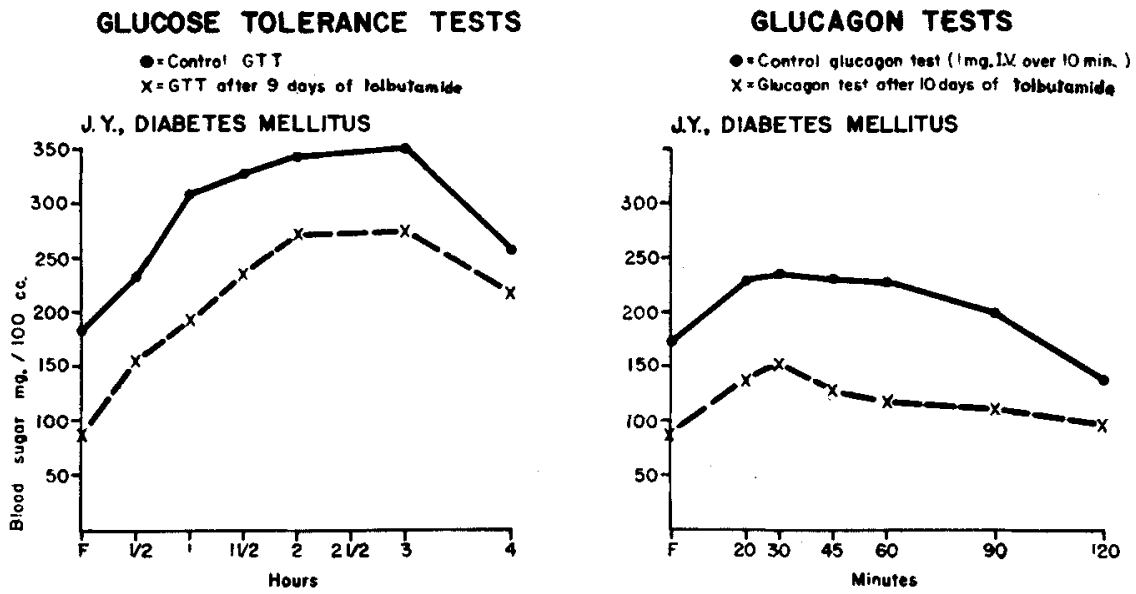

Figure 3. Effect of tolbutamide on glucose tolerance and hyperglycemia produced by glucagon in a diabetic patient.

the same level of dosage, tolbutamide was less effective than carbutamide in reducing the daily fasting blood sugar. ${ }^{1}$

FIgURE 2 demonstrates that administration of tolbutamide to a mild diabetic produced a decrease in levels of fasting blood sugar from the hyperglycemic into the normal range.

FIgURE 3 shows that glucose tolerance was not altered in this patient by the administration of tolbutamide for 9 days, even though the fasting blood sugar was then in the normal range. Glucose tolerance was also not influenced significantly during the administration of sulfonylurea compounds to healthy individuals. ${ }^{1}$

In FIGURE 4 we see that intramuscular administration of adrenalin produced the same rise in blood sugar in a normal male, whether given before administration of carbutamide or after the drug had effected a lowering of the blood sugar in the fasting state. Similarly, the hyperglycemic response to intravenously administered glucagon was not blocked by administration of these drugs in normal subjects, ${ }^{1}$ or in the diabetic patient (FIGURE 3 ).

The sulfonylurea drugs did not potentiate the activity of exogenous insulin in normal males or in diabetic subjects.

FIGURE 5 shows the results of insulin tolerance tests performed in a normal male. The solid line represents the control insulin tolerance test. The line connecting the open circles shows the blood sugar curve obtained during the carbutamide period, but without administration of insulin. Administered insulin at this time was no more effective than it had been before carbutamide had produced a hypoglycemic effect, as shown by the line connecting the crosses.

Figure 6 shows similar data obtained in a diabetic. The middle curve represents the results of a standard insulin tolerance test. The lower 2 curves depict the results of insulin tolerance tests performed after administration of 


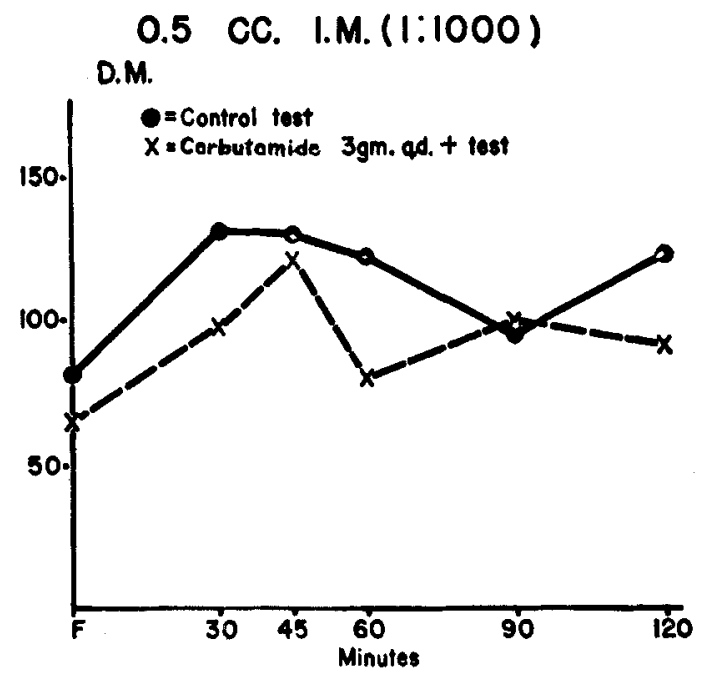

FIGURE 4. Effect of carbutamide on hyperglycemia produced by adrenalin in a norma subject.
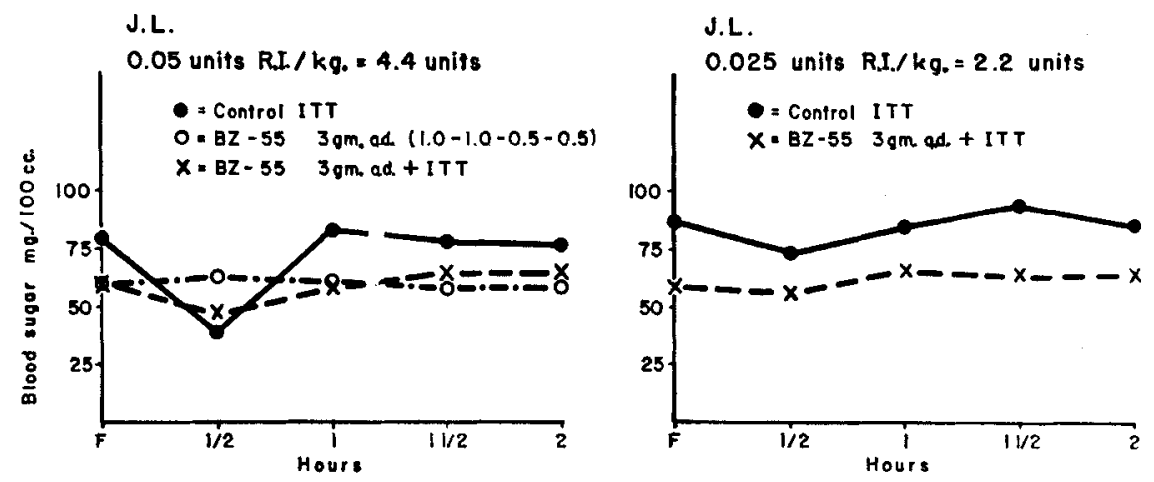

FigURE 5. Effect of carbutamide (BZ-55) on an insulin tolerance test in a normal subject.

tolbutamide for 4 or 5 days, respectively. Again, no potentiation of insulin activity is demonstrated.

In addition, in 3 of our diabetic patients in whom the drugs did not produce a lowering of blood sugar, there was no difference in insulin requirement whether the diabetes was controlled with insulin plus sulfonylurea or with insulin alone. One of these 3 patients is the boy with panhypopituitarism and diabetes, who is very sensitive to insulin and in whom any potentiation of insulin activity should have been very easily observed.

That decreased function of the pituitary-adrenal system is not the mode of action of these compounds is indicated by the following observations:

(1) No significant changes in renal excretion of 17 -hydroxycorticoids or 


\section{O.I Unit insulin/kg.}

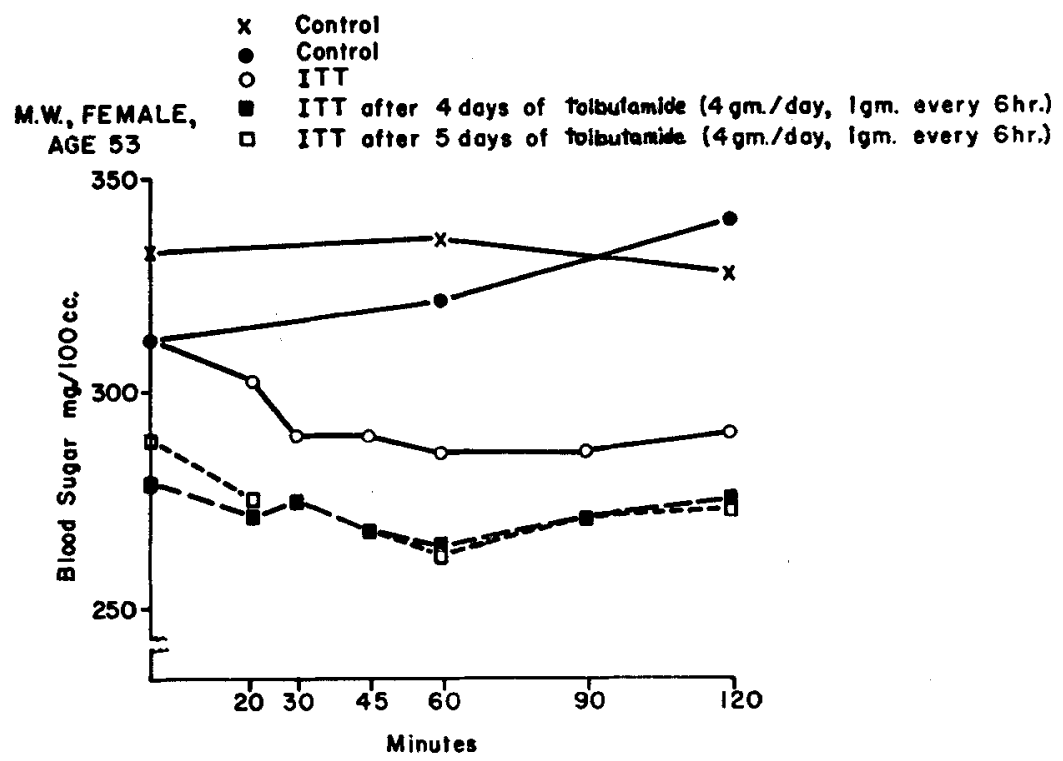

Figure 6. Effect of tolbutamide on an insulin tolerance test in a diabetic subject.

17-ketosteroids could be demonstrated in healthy men or in diabetic patients during the administration of the drugs. ${ }^{1}$

(2) There were no significant changes in the balances of nitrogen, sodium, chloride, or potassium on administration of the sulfonylureas. ${ }^{1}$

(3) In the patient with coexisting diabetes mellitus and Addison's disease, administration of tolbutamide reduced the level of fasting blood sugar from about 150 to $110 \mathrm{mg}$. per cent, despite constant replacement therapy with hydrocortisone and $9 \alpha$-fluorohydrocortisone. Withdrawal of the steroids for 2 days did not potentiate the hypoglycemic effect of tolbutamide in spite of the development of severe adrenal insufficiency. ${ }^{1}$

(4) In 5 nondiabetic patients with severe adrenal insufficiency, intravenously administered sodium tolbutamide produced a similar hypoglycemic effect whether the patients were maintained on hydrocortisone and $9 \alpha$-fluorohydrocortisone or with deoxycorticosterone alone.

As shown in FIGURE 7 , the sulfonylurea compounds do not act by blocking the peripheral effects of adrenocortical steroids. At a time when carbutamide had produced a definite hypoglycemic effect, the administration of $100 \mathrm{mg}$. of Prednisolone for 2 days produced the same rise in fasting blood sugar and the same loss of carbohydrate tolerance as when Prednisolone was given by itself. The sulfonylureas did not alter any of the metabolic changes produced by Prednisolone. ${ }^{1}$

The sulfonylurea compounds are not substitutes for insulin. Carbutamide had no effect in the pancreatectomized patient. In the unstable diabetic, 


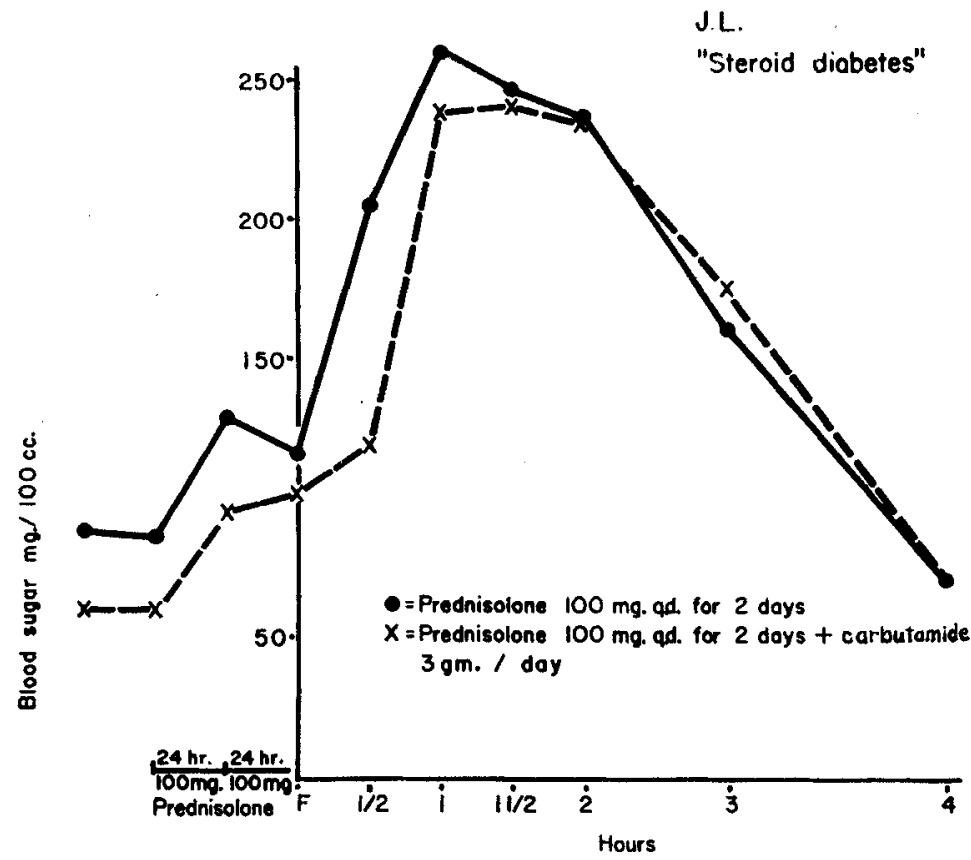

Figure 7. Fffect of Prednisolone on fasting blood sugar and glucose tolerance before and during administration of carbutamicle.

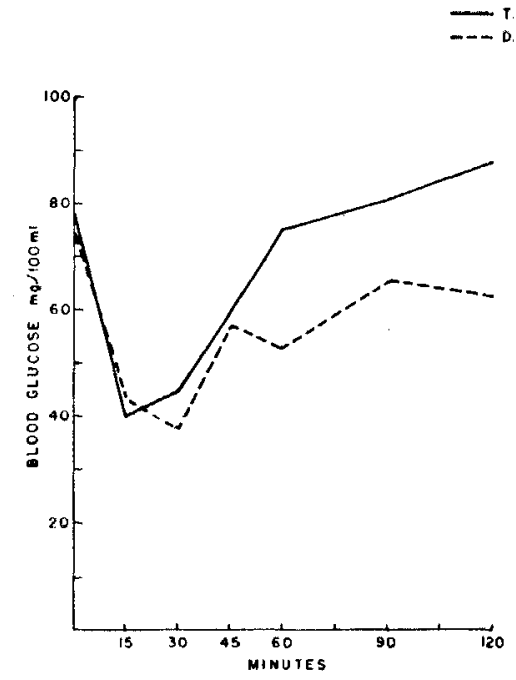

Sodium tolbutamide I am tiv

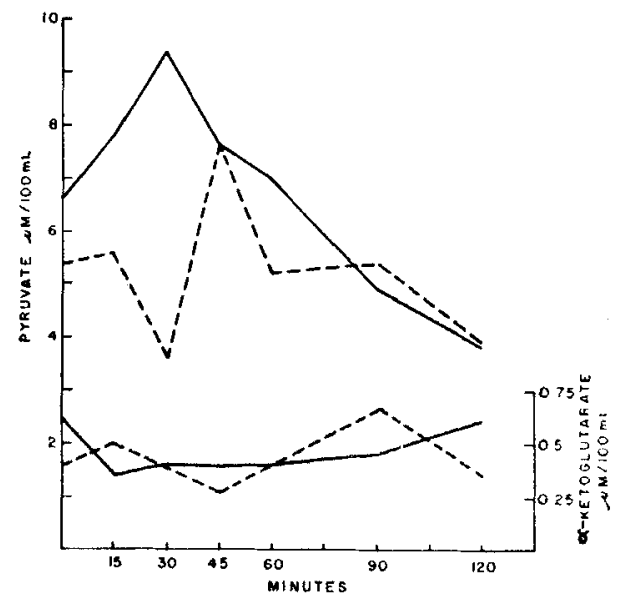

FIGURE 8. Effects of intravenous administration of insulin and of sodium tolbutamide on the blood levels of glucose, pyruvate, and $\alpha$-ketoglutarate. 
Tolbutamide
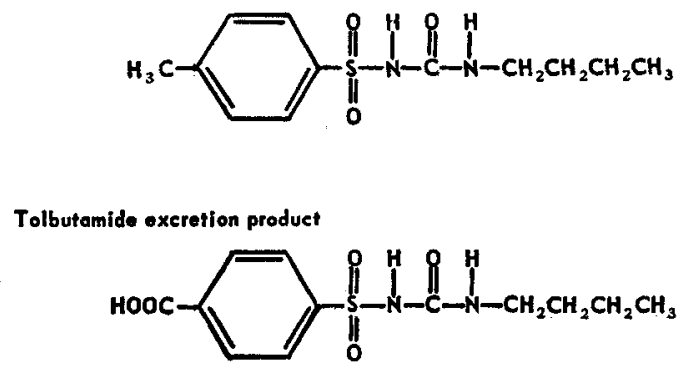

Figure 9

withdrawal of insulin and administration of either carbutamide or tolbutamide resulted in hyperglycemia, glycosuria (which at times equalled the intake of carbohydrate), ketonuria, and negative balances for nitrogen, sodium, and potassium. ${ }^{1}$

FIGURE 8 shows an example of the findings obtained during 8 intravenous insulin tolerance tests and 7 intravenous tolbutamide tests performed in normal subjects. Hypoglycemia induced by intravenous administration of insulin was associated with an initial rise in blood pyruvate. In contrast, when hypoglycemia was induced by intravenous administration of sodium tolbutamide the earliest change in levels of blood pyruvate was a decrease. ${ }^{2}$ These differences suggest that the immediate hypoglycemia induced by administration of insulin on the one hand, and of tolbutamide on the other, occurs via different mechanisms. ${ }^{2}$

During oral administration of tolbutamide it was noted that, upon acidification of the urine to $p \mathrm{H} 5.2$ or below, a precipitate appeared. At $p \mathrm{H} 3$ precipitation was fairly complete. Subsequently, a crystalline compound was isolated with a melting point different from that of tolbutamide. In cooperation with Struck, Wright, and Johnson of The Upjohn Laboratories, this urinary excretion product of tolbutamide has been identified as a carboxylic acid derived by oxidation of the methyl group linked to the aromatic ring (FIGURE 9). ${ }^{3}$

When tolbutamide was administered to normal subjects at a level of 3.0 to $6.0 \mathrm{gm}$./day, 70 to 80 per cent was excreted in the urine as this excretory product. When 3 to $4 \mathrm{gm}$./day was administered orally to diabetic subjects, excretion as the metabolite ranged between 24 and 67 per cent. This material is very likely the principal excretion product of tolbutamide in the human. ${ }^{1}$

Intravenous administration of the pure tolbutamide excretion product as the sodium salt to 4 normal subjects and 1 diabetic patient in a dosage of 1 to $3 \mathrm{gm}$. failed to elicit any blood-sugar-lowering effect. Oral administration of $6 \mathrm{gm}$. of the excretion product daily for 3 days in 4 divided doses to a normal subject likewise failed to influence the level of fasting blood sugar. ${ }^{1}$

\section{Summary and Conclusion}

The data indicate that the sulfonylurea compounds do not (1) suppress the pituitary-adrenal system, (2) antagonize the peripheral effects of adrenal cor- 
ticoids, (3) block the hyperglycemic effects of glucagon and adrenalin, (4) potentiate the activity of exogenous insulin, and that (5) they are not insulin substitutes. Thus, the blood-sugar-lowering property of these compounds is achieved via another mechanism.

The contrasting initial changes in blood pyruvate level associated with hypoglycemia induced by insulin and tolbutamide, respectively, suggest that the sulfonylureas produce acute hypoglycemia by a mechanism other than the rapid release of endogenous insulin.

When tolbutamide is administered, a carboxylic acid derivative of this compound is excreted in urine as a major excretory product.

\section{References}

1. Fajans, S. S., L. H. Louis, H. S. Seltzer, R. D. Johnson, R. D. Gittler, A. R. Hennes, B. L. Wajchenberg, I. P. Ackerman \& J. W. Conn. 1956. Metabolic effects of arylsulfonylurea compounds in normal men and in diabetic subjects. Metabolism. 5: 820 .

2. Hennes, A. R., B. L. Wajchenberg, S. S. Fajans \& J. W. Conn. 1957. Comparative effects of insulin and Orinase on blood levels of pyruvate and alpha-ketoglutarate in normal subjects. Metabolism. 6:63.

3. Louis, L. H., S. S. Fajans, J. W. Conn, W. A. Struck, J. B. Wright \& J. L. Johnson. 1956. The structure of a urinary excretion product of 1-butyl-3-p-tolylsulfonylurea (Orinase), J. Am. Chem. Soc. 78: 5701. 